\title{
A reestruturação dos papéis de gênero e a criação das novas masculinidades
}

\author{
Restructuring of gender roles and \\ creating new masculinities
}

\section{Gabriela Rocha Santana' ${ }^{1}$ Worney Ferreira Brito 2 (1) Wellington Danilo Soares ${ }^{3}$ (1)}

1-2Faculdade de Saúde e Humanidades Ibituruna (Montes Claros). Minas Gerais, Brasil. gabriela.santana790@gmail.com, worney.brito@fasi.edu.br ${ }^{3}$ Autor para correspondência. Faculdade de Saúde e Humanidades Ibituruna (Montes Claros). Minas Gerais, Brasil. wdansoa@yahoo.com.br

RESUMO | OBJETIVO: Identificar a visão do homem cisgênero diante dos novos papéis de gênero na sociedade brasileira contemporânea e da construção das novas masculinidades. MÉTODO: Trata de uma pesquisa descritiva, quantitativa e corte transversal, composta por uma amostra de 38 universitários do sexo masculino, com idade igual ou superior a 18 anos, acadêmicos dos diversos cursos de uma universidade pública estadual da cidade de Montes Claros - MG. O instrumento utilizado foi um questionário semiestruturado contendo vinte e três perguntas fechadas. RESULTADOS: Foi possível identificar um maior retraimento por parte dos sujeitos pretos que, em sua maioria (62,5\%), afirmam não falarem sobre sentimentos. A maior discrepância observada se relaciona com as áreas de estudo, sendo que acadêmicos do Centro de Ciências Sociais Aplicadas, Centro de Ciências Exatas e de Tecnologia e Centro de Ciências Biológicas e da Saúde afirmam ter dificuldade em ser e fazer o que desejam por receio da reação das pessoas, enquanto os do Cento de Ciências Humanas dizem nunca ter essa dificuldade, além de ser o único centro que quase nunca busca se informar sobre as novas construções sociais dos papéis de gênero. CONCLUSÃO: Os resultados obtidos evidenciam as diferenças promovidas pela área de estudo como mais influentes do que a raça - não ignorando sua influência- e podem apontar um caminho para expandir os debates sobre papéis de gênero entre grupos de homens cisgênero, mesclando os debates de cada grupo a fim de encontrar o equilíbrio entre informação e posicionamento na sociedade.

PALAVRAS-CHAVE: Gênero. Crise de identidade. Masculinidade.

\begin{abstract}
OBJECTIVE: Identify the cisgender man's view before the new gender roles in contemporary Brazilian society and the construction of new masculinities. METHOD: This study is a descriptive, quantitative and cross-sectional analysis, composed of a sample of 38 male students aged 18 years or older from different courses at a public state university at Montes Claros, Minas Gerais, Brazil. The research was based on a semi-structured questionnaire containing twenty-three objective questions. RESULTS: It was possible identifying a greater return on the part of black individuals. Most of them $(62.5 \%)$ affirm they usually don't talk about feelings. The biggest discrepancy was observed among students from different areas of study. Students from Social Sciences, Math and Technology and Health Sciences claim to have difficulties in being and doing what they want to because of people's reactions. On the other hand, students from Human Sciences said they have never had that difficulty, besides those students affirm they hardly ever seek information about the new social constructions of gender roles. CONCLUSION: Results obtained show area of study as more influential than race - not ignoring their influence - and may indicate an alternative to expand debates about gender roles among groups of cisgender men, mixing debates of each group in order to find a balance between information and its place in society.
\end{abstract}

KEYWORDS: Genre. Identity crisis. Masculinity. 


\section{Introdução}

Para se falar em gênero é necessário pensar em poder. As relações de poder se estruturam nas divisões de gênero - considerando poder na interpretação de Foucault feita em 1988 enquanto algo que se exerça nas relações sociais; não como maligno, mas sim como algo calculado e com objetivos coletivos - e essas divisões se reconstroem ao passar dos anos, deixando de ser algo que o sujeito possui e passando a ser algo que ele é.

Reforçando essa compreensão, Lima e Belo (2019) afirmam que determinar que um corpo é de um ou de outro sexo traz consigo uma descrição carregada de conceitos predefinidos sobre o que se deve ser, há uma categorização do sujeito que deve se encaixar no binarismo macho-fêmea, ignorando suas diversas compreensões subjetivas.

A construção da imagem feminina é debatida por Deifelt (2019) em sua obra partindo do imaginário infantil moldado por contos de fadas. A mulher é abordada como aquela que espera o amor eterno que estará naquele que a salvar, enquanto o homem se apresenta como aquele dotado de coragem para salvar a moça frágil. Como consequência, a imagem dos contos é projetada ao mundo real e a sociedade espera comportamentos equivalentes.

Com o passar dos anos, o conceito de gênero foi sendo modificado e desvinculado da questão biológica, voltando-se exclusivamente para o âmbito social da identidade subjetiva de mulheres e homens e permanece em constante mudança (Silva \& Brabo, 2016).

Furlin (2016) enfatiza que através da discussão de gênero, o movimento feminista estrutura a problematização sobre os papéis sociais desiguais que construíram as sociedades a partir dos anos, ansiando relações sociais igualitárias. Essa foi a abertura dos caminhos para a desconstrução e desnaturalização dos conceitos atribuídos ao feminino e ao masculino.

Visto que a busca pela desconstrução do conceito biologicista de gênero origina-se, como afirma Silva (2006), principalmente, de grupos feministas, como o homem cisgênero se coloca diante desses novos moldes - ou da falta deles? Como consequência das mudanças culturais, o homem - e será tratado neste estudo por homem aquele cisgênero - se viu em crise; o que desencadeou a criação de clubes de retomada da masculinidade tradicional e também de grupos de discussão e psicoterapia para debater sobre os novos modelos de masculinidade, ambos formados exclusivamente por homens.

Em 2015, Silva, assim como Silva e Macedo em 2019, discute sobre as novas construções de gênero sob um novo parâmetro mais reflexivo e de menos repetição de costumes. A masculinidade tradicional não é uma regra e, portanto, pode ser refeita em novos moldes o quanto for necessário para a saúde mental dos sujeitos.

Em seu trabalho, Boris, Bloc e Teófilo (2012) reforçam o debate sobre a crise da subjetividade masculina elucidando através do patriarcado a questão em discussão. Embora a sociedade esteja mais flexível, ainda é considerado ser menos homem aquele indivíduo que expressa capacidades atribuídas culturalmente ao feminino como o cuidado emocional, o choro, executar tarefas domésticas, etc. Como reforçado por Pongeluppe e Milani (2017) ao abordarem o homem enquanto negativo, uma vez que ele precisa provar ao longo da sua vida não ser uma mulher, não ser homossexual, não ser feminino.

A partir do mesmo entendimento, Betim e Lurke (2019) discutem a repressão que homens sofrem ainda na infância em relação a seus afetos e relacionam-na com os altos índices de violência protagonizada por eles. A perpetuação de papéis de gênero fortalece os padrões de comportamento e a latente necessidade de destacar estar no lugar socialmente "certo".

Nesse contexto de desconstrução, o presente estudo objetivou identificar a visão do homem cisgênero diante dos novos papéis de gênero na sociedade brasileira contemporânea e da construção de novas masculinidades, considerando sua posição dentro destes processos.

Discutir sobre a reformulação dos papéis de gênero postula uma análise sobre o caminho que tem sido cursado e seus meios, bem como os sujeitos que acabam ficando para trás. Nesta perspectiva, o presente estudo se justifica pela necessidade de se compreender o contexto engendrado pelo movimento feminista visto através do máximo de ângulos possíveis, englobando os sujeitos para além do seu papel préestabelecido socialmente. 
Ampliar o leque de análise significa incluir na discussão o fator racial que possui influência também sobre os papéis de gênero. $O$ feminino preto e branco, bem como o masculino preto e branco são culturalmente diferentes. Mesmo de forma mascarada, o homem preto é mais cobrado em relação a sua virilidade do que o homem branco, por exemplo. Enquanto a muIher preta é ainda mais desvalorizada e incapacitada aos olhos da sociedade do que a mulher branca (Conrado \& Ribeiro, 2017).

\section{Métodos}

A amostra foi composta por 38 acadêmicos dos diversos cursos da Universidade Estadual de Montes Claros - UNIMONTES, sexo masculino, cisgênero, com idade igual ou superior a 18 anos. Foram incluídos todos acadêmicos que responderam o questionário online até o dia 25 de março e que aceitaram participar de forma voluntária da pesquisa, e excluídos aqueles menores de 18 anos, os que não assinaram o TCLE e os homens não cisgênero.

O instrumento utilizado foi um questionário semiestruturado com 23 (vinte e três) perguntas fechadas que exploram o entendimento dos homens sobre sua posição sociedade atual diante dos novos papéis de gênero construídos a partir das primeiras discussões levantadas pelo movimento feminista.

O presente estudo foi submetido e aprovado pelo Comitê de Ética em Pesquisa da Universidade
Estadual de Montes Claros - Unimontes sob o parecer 3.771.637/2019 (CAAE 26664819.5.0000.5146). Trata de uma pesquisa de caráter descritivo, com abordagem quantitativa e corte transversal.

Após a autorização da direção da instituição pesquisada, os questionários foram compartilhados via link do Google Forms para os coordenadores de todos os centros acadêmicos da universidade pesquisada que os repassaram aos acadêmicos. Aqueles que aceitaram participar de forma voluntária assinalaram a concordância com o termo de consentimento livre e esclarecido. A fase de coleta de dados ocorreu no mês de março de 2020.

Após a coleta de dados, foram feitas análises descritivas com valores de frequência, porcentagem, média e desvio padrão. Todo o procedimento estatístico foi realizado através do Statistical Package for the Social Sciences (SPSS) versão 22.0 para Windows.

\section{Resultados}

O presente estudo avaliou 38 homens cisgêneros acadêmicos da Universidade Estadual de Montes Claros - UNIMONTES, com idade média entre 18 e 28 anos dos quatro centros de especialidade: Centro de Ciências Sociais Aplicadas (CCSA), Centro de Ciências Humanas $(\mathrm{CCH})$, Centro de Ciências Exatas e de Tecnologia (CCET) e Centro de Ciências Biológicas e da Saúde (CCBS).

Tabela 1. Tabela de variáveis com dados em valores de frequência real e absoluta que caracterizam o grupo amostral $(n=38)$

\begin{tabular}{|c|c|c|}
\hline VARIÁVEL & OPÇÕES & $N-\%$ \\
\hline Idade & $\begin{array}{c}\text { De } 18 \text { a } 28 \text { anos } \\
\text { De } 29 \text { a } 38 \text { anos } \\
\text { Acima de } 39\end{array}$ & $\begin{array}{c}35-92,1 \\
2-5,2 \\
1-2,7\end{array}$ \\
\hline Etnia & $\begin{array}{l}\text { Branco } \\
\text { Pardo } \\
\text { Preto }\end{array}$ & $\begin{array}{c}13-34,2 \\
17-44,7 \\
8-21,1\end{array}$ \\
\hline Centro & $\begin{array}{l}\text { CCSA } \\
\mathrm{CCH} \\
\text { CCET } \\
\text { CCBS }\end{array}$ & $\begin{array}{c}15-39,4 \\
10-26,3 \\
10-26,3 \\
3-8,0\end{array}$ \\
\hline
\end{tabular}


A maioria dos avaliados encaixaram entre 18 e 28 anos $(92,1 \%)$ e quase metade era de cor parda $(44,7 \%)$. Já a distribuição de sujeitos entre os centros se manteve mais equilibrada, com maior participação dos universitários dos cursos do Centro de Ciências Sociais Aplicadas (CCSA) e menor participação dos cursos da área da saúde, Centro de Ciências Biológicas e da Saúde (CCBS).

\section{Discussão}

O presente estudo tem por objetivo identificar a visão do homem cisgênero diante dos novos papéis de gênero na sociedade brasileira contemporânea e da construção de novas masculinidades, considerando sua posição dentro destes processos. A partir disso, será possível enriquecer os debates sobre o binarismo macho-fêmea tão enraizado na cultura brasileira ainda nos dias de hoje e fortalecer os processos de mudança do que é ser feminino e masculino.

Ao categorizar as análises por raça e área de estudo, foram obtidos dados que demonstram visões diferentes de acordo com os critérios avaliados, o que reforça a necessidade de se ampliar os estudos para que a discussão se torne cada vez mais rica e coerente.

Os três grupos étnico-raciais concordam que o machismo faz mal para a mulher $(95 \%$ dos entrevistados) e que, quase sempre, faz mal para o homem também (73,5\%). Destes grupos, a maioria dos pretos $(62,5 \%)$ não se sente limitações quanto a sua forma de expressão, todavia, a mesma porcentagem deles quase nunca conversa sobre dificuldades e sentimentos com outros homens. O silêncio de homens pretos pode ser entendido como consequência de uma longa história de construção racial em que o preto não possui espaço de fala, como Andreo, Peres, Tokuda e Souza (2016) abordam em seu estudo.

Um dado a ser observado é que pretos $(62,5)$, ao contrário de pardos e brancos, raramente buscam se informar sobre as mudanças sociais relacionadas aos papéis de gênero. A desinformação prejudica o entendimento e a realocação do homem diante das transformações dos papéis feminino e masculino.
As três raças acreditam $(81,5 \%)$ que os homens têm mais benefícios que as mulheres, mesmo acreditando que o homem não é superior a elas (89,5\%). Foi possível verificar também que, apesar das mudanças no papel do homem percebido por eles nos últimos cinco anos, a sociedade brasileira ainda é machista.

Os homens pardos demonstram maior preocupação em se expressar e seguir seus desejos por receio da não aceitação social (79\%), um contexto construído desde o início da história do Brasil, como reforçam Figueiredo e Grosfoguel (2009).

Quando avaliadas em relação à área de estudo, duas perguntas se destacam em discrepância. A maioria dos acadêmicos dos centros CCSA, CCET e CCBS afirma ter dificuldade em ser e fazer o que desejam por receio da reação das pessoas, enquanto os do $\mathrm{CCH}$ dizem nunca ter essa dificuldade (70\%). Entretanto, dos três centros, este é o que menos busca se informar sobre as novas construções sociais dos papéis de gênero (60\%).

A partir dessa análise, é possível fazer uma relação do conhecimento das reformulações dos papéis de gênero com as formas de expressão dos homens. Aqueles que se informam mais conhecem as implicações sociais e os novos arranjos do seu papel masculino, ou seja, estudar os impactos do machismo sobre homens e mulheres pode contribuir para um cuidado na forma como um homem se posiciona na sociedade - o que não invalida o sofrimento desses sujeitos, como abordado nos estudos de Silva (2019) e de Betim e Lurke (2019), por não saberem seu lugar na nova sociedade.

O Brasil ainda vive um sistema patriarcal, apesar das mudanças que vêm acontecendo desde a criação do Código Civil de 1926 brasileiro que estabelecia a superioridade masculina até mesmo pela força física, a família sendo identificada pelo nome do marido e a mulher obrigada a adotar seu sobrenome (Santana, Rios \& Menezes, 2019). A saída da mulher do lugar de submissão e do homem do lugar de dominante faz parte de uma desconstrução gradativa que vem acontecendo no nosso país e se fortalecendo com as reconstruções dos papéis sociais (Freitas, Félix \& Carvalho, 2018). 
Diante da pandemia de COVID-19 vivenciada durante a realização da fase final do presente estudo, a amostra foi reduzida por dificuldade de acesso ao grupo alvo da pesquisa e o questionário foi aplicado via formulário online, respeitando a determinação da Organização Mundial de Saúde e demais órgãos competentes de manter o distanciamento social.

\section{Conclusão}

Com base no presente estudo, foi possível demonstrar a mudança que vem acontecendo na construção das masculinidades no Brasil e que as variáveis de raça, idade ou área de estudo pouco interferem nessas transformações, sendo mais relevante o nível de busca por novos conhecimentos na área. Ainda há um longo caminho a ser percorrido até se alcançar a igualdade de gênero, mas a caminhada já começou e está contando cada vez mais com a participação essencial dos homens.

Portanto, é imprescindível que se façam mais estudos na área a fim de entender esses novos arranjos e como o homem se vê diante deles, a fim de promover uma mudança efetiva e reduzir o sofrimento psíquico desses sujeitos durante sua adaptação e reformulação.

\section{Contribuições dos autores}

Santana GR participou da concepção, delineamento, busca, coleta e análise estatística dos dados da pesquisa, elaboração do questionário, interpretação dos resultados e redação do artigo científico. Brito WF participou da busca e análise dos dados da pesquisa, revisão de conteúdo, elaboração do questionário e interpretação dos resultados. Soares WD participou da busca, coleta e análise estatística dos dados da pesquisa e interpretação dos resultados.

\section{Conflitos de interesses}

Nenhum conflito financeiro, legal ou político envolvendo terceiros (governo, empresas e fundações privadas, etc.) foi declarado para nenhum aspecto do trabalho submetido (incluindo, mas não se limitando a subvenções e financiamentos, participação em conselho consultivo, desenho de estudo, preparação de manuscrito, análise estatística, etc.).

\section{Referências}

Andrêo, C., Peres, W. S., Tokuda, A. M. P., \& Souza, L. L. (2016). Homofobia na construção das masculinidades hegemônicas: queerizando as hierarquias entre gêneros. Estudos e Pesquisas em Psicologia, 16(1), 46-67. https://doi. org/10.12957/epp.2016.24756

Betim, D., \& Lurke, B. O. (2019). Atos de fala sobre gênero e sexualidade: a necessidade do contradiscurso. Revista $X$, 14(4), 222-239. http://dx.doi.org/10.5380/rvx.v14i4.66127

Boris, G. D. J. B., Bloc, L. G., \& Teófilo, MCC (2012). Os rituais da construção da subjetividade masculina. O público e o privado, 19, 17-32. http://www.seer.uece.br/?journal=opublicoeoprivado\&page $=$ article\&op=view\&path\%5B\%5D=334\&path $\% 5 B \% 5 D=498$

Conrado, M., \& Ribeiro A. A. M. (2017). Homem negro, homem negro: masculinidades e feminismo negro em debate. Estudos Feministas, 25(1),73-97. https://doi.org/10.1590/ 1806-9584.2017v25n1p73

Deifelt, W. (2019). Bela, recatada e do lar. Revista de estudos feministas em teologia e religião, 5(1), 06-19. http://periodicos. est.edu.br/index.php/genero/article/view/3690

Figueiredo, A., \& Grosfoguel, R. (2009). Racismo à brasileira ou racismo sem racistas: colonialidade do poder e a negação do racismo no espaço universitário. Sociedade e Cultura, 12(2), 223-233. https://doi.org/10.5216/sec.v12i2.9096

Foucault, M. (1999). História da sexualidade l: a vontade de saber. (M. Tereza, \& G. Albuquerque, Trad.). Edições Graal.

Freitas, M, J. T., Silva, J. F., \& Carvalho, M. E. P. (2018). Homens podem ser feministas? O

pioneirismo dos estudos de masculinidades no Nordeste do Brasil. Revista de Educação Pública, 27(66). https://doi. org/10.29286/rep.v27i66.7013

Furlin, N. (2016). A produção do feminino: representações de gênero no discurso da teologia

católica tradicional. Estudos de Sociologia, 2(22). https://periodicos.ufpe.br/revistas/revsocio/article/view/235744

Lei $n^{\circ} 3.071$, de $1^{\circ}$ de janeiro de 1916. Código Civil de 1916. http://www.planalto.gov.br/ccivil_03/leis/L3071.htm

Lima, V. M., \& Belo, F. R. R. (2019). Gênero, sexualidade e o sexual: o sujeito entre Butler,

Foucault e Laplanche. Psicologia em Estudo, 24, 1-15. http://dx. doi.org/10.4025/1807-0329e41962 
Pongellupe, M. A. B., \& Milani, D. R. C. (2017). A masculinidade hegemônica advinda dos enredos midiáticos - um jeito de ser masculino. Revista Brasileira de Sexualidade Humana, 28(2), 08-16. https://doi.org/10.35919/rbsh.v28i2.17

Santana, I. H. B., Rios, L. F., \& Menezes, J. A. (2017). Genealogia do Desquite no Brasil. Revista Psicologia Política, 17(39), 340350. http://pepsic.bvsalud.org/scielo.php?script=sci_arttext\&pid=S1519-549X2017000200012\&lng=pt\&nrm=iso

Silva, C. S. (2019). Identidades: relação entre as masculinidades, gênero e violência. Revista X, 14(4), 184-199. http://dx.doi. org/10.5380/rvx.v14i4.66107

Silva, F. A. (2015). Masculinidades críticas e a proposição analítica e relacional nas contemporâneas discussões de gênero. Revista Estudos Feministas, 23(3), 1023-1044. http://dx.doi. org/10.1590/0104.026X2015v23n3p1026
Silva, M. E. F., \& Brabo, T. S. A. M. (2016). A introdução dos papéis de gênero na infância: brinquedo de menina e/ou de menino? Trama Interdisciplinar, 7(3), 127-140. http://editorarevistas.mackenzie.br/index.php/tint/article/view/9856

Silva, N. D. B., \& Macedo, J. P. S. (2019). Novas Vozes no Cuidado: Uma Revisão Sistemática Sobre a Produção Científica no Campo de Discussão Entre Masculinidade e Cuidado. Revista FSA, 16(2), 318-339. http://dx.doi. org/10.12819/2019.16.2.17

Silva, S. G. (2006). A crise da masculinidade: uma crítica à identidade de gênero e à literatura masculinista. Psicologia, Ciência e Profissão, 26(1), 118-131. http://dx.doi.org/10.1590/ S1414-98932006000100011 